This item was submitted to Loughborough's Research Repository by the author.

Items in Figshare are protected by copyright, with all rights reserved, unless otherwise indicated.

\title{
An integrated model highlighting information literacy and knowledge formation in information behaviour
}

PLEASE CITE THE PUBLISHED VERSION

https://doi.org/10.1108/AJIM-09-2016-0148

PUBLISHER

Emerald

VERSION

AM (Accepted Manuscript)

\section{PUBLISHER STATEMENT}

This work is made available according to the conditions of the Creative Commons Attribution-NonCommercialNoDerivatives 4.0 International (CC BY-NC-ND 4.0) licence. Full details of this licence are available at: https://creativecommons.org/licenses/by-nc-nd/4.0/

\section{LICENCE}

CC BY-NC-ND 4.0

\section{REPOSITORY RECORD}

Ibenne, Samuel K., Boyka Simeonova, Janet Harrison, and Mark Hepworth. 2019. "An Integrated Model Highlighting Information Literacy and Knowledge Formation in Information Behaviour”. figshare. https://hdl.handle.net/2134/24847. 


\title{
An integrated model highlighting information literacy and knowledge formation in information behaviour
}

\begin{abstract}
Purpose

This paper reviews key models of people's information behaviour (IB) exploring the integration of the concepts of information literacy (IL) and knowledge in their designs. Scholarly perspectives portray information literacy as providing individuals with capacity for good information practices that result in generating new knowledge. It is surprising that this important perspective is not reflected in the reviewed information behaviour models. This paper contributes to the literature base by proposing a new model highlighting IL and knowledge as important concepts within the information behaviour discourse.
\end{abstract}

Approach

A discourse of the integration of information literacy and knowledge, which are integral factors, associated with IB, in selected IB models.

\section{Findings}

Identifying a need for information and understanding its context is an IL attribute. IL underpins information behaviour in providing awareness of information sources; how to search and use information appropriately for solving information needs and leveraging generated new knowledge. The generation of new knowledge results from using information, in a process that combines with sense-making and adaption. Correspondingly, the knowledge that develops, increases capability for sense-making and adaptation of information to suit various contexts of need; iteratively.

\section{Originality/value}

A new model of information behaviour; the Causative and Outcome Factors of Information Behaviour (COFIB) is proposed. COFIB stresses that information literacy and knowledge are prominent factors within the general framework of people's information behaviour. The model emphasises knowledge generation as the outcome of information behaviour, applied in solving problems within specific contexts.

Keywords: information behaviour, information literacy, information needs, knowledge, model, COFIB

\section{Introduction}

The concepts of information needs, information behaviour and information use as well as their relationship appear to have been well explored in the literature (e.g. Wilson, 1997; Case, 2007; Niu and Hemminger, 2012; Clarke et al., 2013). However, the majority of the models portray information behaviour as a linear and do not seem to establish how information literacy and knowledge fit within people's information behaviour.

This paper argues that the importance of information literacy and knowledge formation needs to be recognised and integrated within IB models. The role of IL in IB is suggested here to be 
two-fold: in recognising the information need and in the ability to interact with information sources.

The perspective canvassed by Welsh and Wright (2010) that it takes an information literate person to realise a genuine need for information reveals the important relationship between information literacy and information need within people's information behaviour. Information literacy is considered as influencing people's information behaviour in the sense that "Information literate people are discerning in their choice of information sources and their use of knowledge...[and] can use information to transform their circumstances, create new knowledge and reach their full potentials" (Secker and Coonan, 2013, p. xv).

Similarly, Hepworth (2000) suggests that the information literate person is one who possesses a balanced and integrated knowledge base, resulting from interactions with different knowledge domains in the information literacy learning process. These interactions foster capacity for understanding the theoretical and practical implications of information use. The literature espouses the constructs of information need (Nui and Hemminger, 2012; Detlor 2003; Case, 2007; Clarke et al., 2013; Cole, 2011), role (Li and Belkin, 2010; Lloyd, 2010a; Nui and Hemminger, 2012), information literacy (Hepworth, 2007; Lloyd 2010a; Hepworth and Walton, 2013), and the knowledge created and shared within communities (Lloyd, 2010), as factors which predispose people's information behaviours within their information environments.

Additionally, whilst IB literature recognises the knowledge gap, which triggers the information need (Dervin, 1980), the production of knowledge as a result of information behaviours and use is an aspect overlooked in IB models.

Given the relationship of information literacy and knowledge to information behaviour, as espoused by aforementioned authors, it is surprising that this perspective has not featured in the design of information behaviour models. This paper begins by probing how previous models linked information literacy and knowledge to people's information behaviour. This is given the aforementioned and similar perspectives such as Horton (2011) who suggests placing emphasis on the relevance of the body of knowledge in information literacy and linking it to specific long-standing goals in all contexts, within the modern Global Information/Knowledge Society (pp. 262 \& 273). Subsequently, a new integrated model is developed, outlining the importance of IL and knowledge formation in IB. 
This paper posits that the gap in the current information behaviour models is that of the third dimension; showing how information behaviour leverages on information literacy, to afford competence for information use and generation of new knowledge, for application in problem-solving contexts. The paper contributes to the literature base by proposing a new information behaviour model entitled the Causative and Outcome Factors of Information Behaviour COFIB (presented in Figure 1) - expressing these links by highlighting information literacy and knowledge as factors integral to the discourse of people's information behaviour.

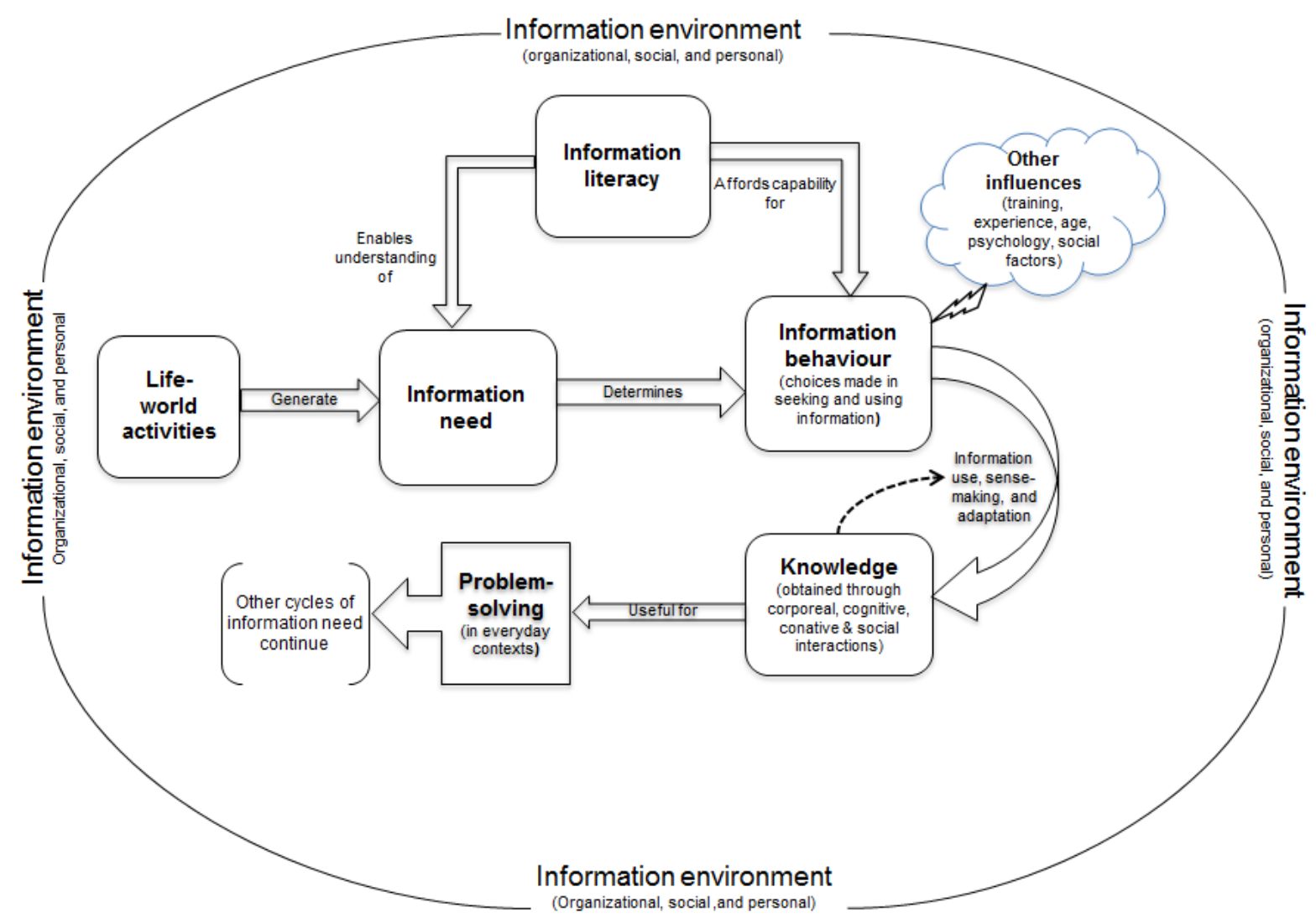

Figure 1: The causative and outcome factors of information behaviour (COFIB) model

\section{Methodology}

This paper reviews selected models of information behaviour for links with information literacy and knowledge formation. Lists of prominent information behaviour models analysed in Wilson (1999) and itemised in Detlor (2003) were used as an initial search of the old and new IB literature. This search identified a number of information behaviour models spanning many decades of scholarly research such as Belkin (1980; 1995); Choo (2006); Cole (2011); 
Dervin (1992); Ingwersen (1996); Kulthau (1991; 1993); Wilson (1981; 1997; 1999; 2000); Niu and Hemminger (2012).

Following the literature review of Information Behaviour modules, the literature was read, re read analysed and discussed at length by the researchers. The development of the criteria to select or reject an IB model was an organic process. Some of the chosen models may appear at first glance to be on the periphery of the IB field, e.g. Cole (2011) and Detlor (2003) however their inclusion in the final selection is deliberate.

Ultimately, the IB models included in the review were premised on relatedness of their designs and discourses to the interest of this paper, which is, linking the concepts of information literacy and knowledge formation to information behaviour. Therefore, the main selection criteria were links to information literacy, or knowledge, or both. This resulted in, the selection of these six models: Belkin (1980); Cole (2011); Detlor (2003); Niu and Hemminger (2012); and, Wilson $(1981,1997)$. The rationale for their selection is provided in Table 1.

Table 1: Rationale and criteria for selecting models.

\begin{tabular}{|c|c|c|c|c|c|}
\hline Author (s) & $\begin{array}{l}\text { Journal and } \\
\text { Year }\end{array}$ & Focus & IL & K & Justification for selection \\
\hline Belkin & $\begin{array}{l}\text { The Canadian } \\
\text { Journal of } \\
\text { Information } \\
\text { Science } \\
\text { Year: } 1980\end{array}$ & $\begin{array}{l}\text { The focus is placed } \\
\text { on the users' } \\
\text { knowledge gap and } \\
\text { its resolution at the } \\
\text { core of an } \\
\text { information need. }\end{array}$ & $\mathrm{X}$ & V & $\begin{array}{l}\text { Whilst Belkin's model does not } \\
\text { account for information literacy, } \\
\text { which could be argued to be an } \\
\text { important part in using an } \\
\text { information retrieval system, the } \\
\text { ASK model provides a good } \\
\text { foundation for understanding } \\
\text { knowledge gaps as triggers for } \\
\text { information needs and the } \\
\text { conceptual state of knowledge } \\
\text { which links to the realization of } \\
\text { this need. }\end{array}$ \\
\hline Wilson & $\begin{array}{l}\text { The Journal of } \\
\text { Documentation } \\
\text { Year: } 1981 \\
\text { Information } \\
\text { Processing and }\end{array}$ & $\begin{array}{lr}\text { Focused } & \text { on } \\
\text { information seeking } \\
\text { behaviour, where } \\
\text { the } 1997 \text { model } \\
\text { specifically } \\
\text { emphasises } \\
\text { barriers the } \\
\text { information }\end{array}$ & $\mathrm{V}$ & $\mathrm{V}$ & $\begin{array}{l}\text { Wilson's models have been } \\
\text { selected as they provide a } \\
\text { foundation for understanding the } \\
\text { role of IL and knowledge, despite } \\
\text { these not being explicitly included } \\
\text { in any of his models. The lack of } \\
\text { information literacy could be seen } \\
\text { as barrier in information seeking. }\end{array}$ \\
\hline
\end{tabular}




\begin{tabular}{|c|c|c|c|c|c|}
\hline & $\begin{array}{l}\text { Management } \\
\text { Year: } 1997\end{array}$ & $\begin{array}{l}\text { seeking. Wilson's } \\
\text { models also } \\
\text { account for the } \\
\text { environment where } \\
\text { the information } \\
\text { need occurs. }\end{array}$ & & & $\begin{array}{l}\text { The models also emphasise on } \\
\text { information use, and feedback } \\
\text { loops, which could help to inform } \\
\text { the role of knowledge in IB } \\
\text { models. }\end{array}$ \\
\hline Detlor & $\begin{array}{l}\text { Information } \\
\text { Systems Journal } \\
\text { Year: } 2003\end{array}$ & $\begin{array}{lr}\text { Focused on } & \text { how } \\
\text { individuals } & \text { within } \\
\text { organisation } & \text { seek } \\
\text { and } & \text { use } \\
\text { information. } & \end{array}$ & $X$ & $\mathrm{~V}$ & $\begin{array}{l}\text { Detlor's model provides a very } \\
\text { good foundation to link use of } \\
\text { information in practice and } \\
\text { knowledge formation. }\end{array}$ \\
\hline Cole & $\begin{array}{l}\text { Journal of the } \\
\text { American } \\
\text { Society for } \\
\text { Information } \\
\text { Science and } \\
\text { Technology } \\
\text { Year: } 2011\end{array}$ & $\begin{array}{l}\text { This paper analyses } \\
\text { eight important } \\
\text { factors/concepts in } \\
\text { IB: information } \\
\text { seeking, search and } \\
\text { use; problem, } \\
\text { problematic } \\
\text { situation and task; } \\
\text { sense making and } \\
\text { evolutionary } \\
\text { adaptation/informat } \\
\text { ion foraging. }\end{array}$ & $X$ & $\mathrm{~V}$ & $\begin{array}{l}\text { The aspects of sense-making and } \\
\text { information adaptation are } \\
\text { particularly useful in outlining } \\
\text { knowledge formation in } \\
\text { information behaviour. }\end{array}$ \\
\hline $\begin{array}{l}\text { Niu } \\
\text { and } \\
\text { Hemminger }\end{array}$ & $\begin{array}{l}\text { Journal of the } \\
\text { American } \\
\text { Society for } \\
\text { Information } \\
\text { Science and } \\
\text { Technology } \\
\text { Year: } 2012\end{array}$ & $\begin{array}{l}\text { Focused on factors } \\
\text { affecting } \\
\text { information seeking } \\
\text { behaviour. }\end{array}$ & $\mathrm{V}$ & $X$ & $\begin{array}{l}\text { Owing to the strong emphasis on } \\
\text { the individual in information } \\
\text { behaviour, could help outline the } \\
\text { aspect of information literacy as a } \\
\text { personal quality. This has not been } \\
\text { made explicit in Niu and } \\
\text { Hemminger's model. }\end{array}$ \\
\hline
\end{tabular}

Belkin (1980) was selected as the foremost IB model which flagged the concept of knowledge by premising its design on a user's knowledge state in anomaly. Wilson's (1981, 1997) models were selected owing to their strong focus on the information seeker/user/context of use. Wilson (1997) specifically identified 'barriers' within the context of information seeking, for the user. The review done in this paper, explores Wilson's (1997) 'barriers' to identify whether information literacy has been included and the impact this has on information use and knowledge formation for the user. Detlor's (2003) model was selected to analyse whether it links knowledge formation with information use, given its emphasis on the existence of a knowledge gap in users and on information use. Cole's (2011) model was 
selected because it includes sense-making and adaptation in its design. This current paper further explores whether these have been related to IL and knowledge. Niu and Hemminger's (2012) model was selected owing to its strong emphasis on the 'person' within the information behaviour framework. This current paper analyses whether a person's information literacy has been integrated within this focus on the person, and the relationship it has with information behaviour.

The review of these models provided some basis for the design of the causative and outcome factors of information behaviour model (COFIB). However the COFIB distinctively highlights the importance of integrating IL and knowledge formation in information behaviour models, which has previously been underplayed.

\section{Perspectives in selected information behaviour models}

\section{Anomalous states of Knowledge (ASK) as a Basis for Information Retrieval (Belkin, 1980)}

Belkin's (1980) popular ASK model distinctively stresses users' anomalous states of knowledge as being at the centre of their need for information. This knowledge in an anomalous state "with respect to the problem faced" (p. 135), i.e., an information need, was presented as a preferable basis for designing information retrieval (IR) systems, than a previous focus on document representation. The anomaly surfaces upon a user's realisation of deficiency or insufficiency in his or her state of knowledge for solving a problem, and then "goes to the IR system to resolve it" [i.e. the anomaly] (p. 135). In this process "the success of the communication [between the user and the IR system] is dependent upon the extent to which the anomaly can be appropriately resolved on the basis of the information provided" ( $p$. $135)$.

Although the ASK model provided a caveat that excluded the reception of knowledge from other non-IR sources, such as "acquisition of knowledge by humans directly from the physical environment" (p. 133) in its scope, it, nonetheless, succinctly placed a knowledge gap and its resolution at the core of an information need. Scholars have explored in many other IB discourses, how information useful for resolving problems is received by humans from other sources other than IR systems (e.g. Hepworth, 2007; Lloyd 2010a; Lloyd 2010b). Belkin's (1980) focus on using IR systems to resolve a knowledge gap, which excludes the reception of information from, for example, social interactions, makes the ASK model unidimensional. The ASK suits the analysis of information transactions within cognitive, system-based, domains alone. Analysing the knowledge generation processes involved in 
resolving knowledge gaps within domains outside the IR system, such as among illiterate groups, would not be appropriate using the ASK model.

The knowledge the user receives, which rectifies the anomalous state of knowledge was not highlighted in the ASK. Being able to demonstrate the processes that result in the formation of knowledge could best have been the salient result for the IR system user, within the ASK model. Although the ASK mentions the solution of the user's problem through using the IR system, it omitted indicating knowledge as the factor that solves this anomaly. This aspect of information behaviour outcome was not explored by the ASK model. It appears an oversight which blurs the importance of the corpus of knowledge generated from the user versus IR system communication, as the main factor which rectifies the anomalous state of knowledge.

\section{A general model of information-seeking behaviour (Wilson, 1981, 1997)}

Following Belkin (1980), others authors continued to analyse the context within which users sought information from diverse standpoints.

Wilson (1981) wrote a seminal paper in the field of information behaviour entitled "On user studies and information needs" enunciating information use as the outcome of informationseeking behaviour, in which the "use' "may satisfy or fail to satisfy the need" (p. 5). Subsequently, Wilson (2000) and authors such as Spink and Cole (2006), have canvassed information use, as the outcome of information behaviour. Spink and Cole (2006) aver that "for millennia humans have sought, organized, and used information as they learned and evolved patterns of human information behaviours to resolve their human problems and survive" (p. 25). They further contextualized people's information behaviour as consisting of three strands of "seeking, searching, and use" (p. 29). Their perspective links information use also directly with information behaviour. This view tends to negate the role of the knowledge generated through information use, sense-making, and adaptation, being the concomitant outcomes of information behaviour; as the basis for contexts of problem-solving and further effective use of information.

Wilson (1981) initiated this thread of thinking by attributing people's information need, which he argues was not specifiable, as the primary prompt of an information-seeking behaviour. Years later, Wilson's (1997) in a revision of Wilson (1981) portrayed the context of information needs, as being "at the root of the problem of information-seeking behaviour" and suggesting further that, the concepts involved in charting an individual's information behaviour were "information need, information seeking, information exchange, and 
information use" (p. 552). Wilson (1997) went further to infer that elements such as: the situation that caused the need; the barriers that may be encountered when engaged in the information task; and, the information behaviour itself, were "the circumstances that give rise to information-seeking behaviour" (p. 552).

This perspective of 'a need' for information for individuals appears to be consistent with the notion of an anomalous state in knowledge postulated earlier in Belkin (1980). This perspective connotes a problematic condition that gives rise to the quest for information to generate new knowledge as the solution. Wilson's models (1981, 1997, 2000) having concluded that that reception and use of information resolves the information need, were all silent on the impact of the information use experience on the user, apart from solving the need. The idea of the formation of new knowledge in the user, resulting from such information-use exercise was not muted.

Wilson (1997) recognised that individuals could encounter 'barriers' within the context of information seeking. These barriers were classified into three: personal, role-related and environmental. Within the personal strand information literacy of the individual was not specifically mentioned. This is a significant omission given the avalanche of perspectives (American Library Association (ALA), 2000; ANZIIL, 2004; Ojedokun, 2007; Lloyd, 2010a; SCONUL, 2011; Walton and Cleland, 2013; Hepworth and Walton, 2013) inferring that information literacy contributes majorly to an individual's possession of effective capabilities in information seeking and its appropriate use. This omission underplays the important contributions of information literacy to an individual's information seeking behaviour, information use, and the formation of new knowledge.

\section{A general model of information use (Detlor, 2003)}

Detlor (2003) portrayed the context of information need in a general model of information use. The model avers that individuals experience information need within a work/social setting context, which triggers information seeking for information use. The model depicts the process which begins with information needs to information seeking and finally terminating at information use, as iterative, with cycles of needs-seeking-use repeating continuously. This echoes the overarching perspective that human information needs exert influence on information behaviour by prompting specific information actions in response to those needs. 
The formation of knowledge would be expected to be clearly portrayed as the outcome of information use Detlor's (2003) model, given his definition of information needs as "where individuals recognize gaps in their states of knowledge and in their ability to make sense of an experience" (p. 116). It, therefore, surprises, that the emphasis in Detlor's (2003) model was not the formation of new knowledge for bridging the knowledge gap inferred. It surmises from the definition that the formation of knowledge in the user, is the end goal of information use in resolving an information need. This factor is a salient omission from the design of Detlor's (2003) model, and it challenges the notion of a gap in knowledge.

\section{Information need as a black box and three categories of information need surrogates (Cole, 2011)}

Cole (2011) presents information need as the "black box" (p. 1217) at the centre of why individuals seek information, and advances three surrogates of information need as consisted of: information behaviours; context; and human condition.

Cole (2011) emphasises understanding the context or the situation which generates the information need, because individuals having information need often are unaware of what would precisely satisfy the need. The author infers further that: a) the analysis of information need should be predicated on the information behaviours which it precipitates, namely, information seeking and use; b) information needs are produced by the diverse contexts of the users, e.g. a problematic situation, problem and task; c) information need is a fundamental factor of the human condition in which information is applied through the twin process of sense-making and adaptation.

Cole (2011) therefore, answers the important question of what prompts the information need or the basis for the information need. The model, however, was silent on the issues of the influences on information behaviour and the outcomes of information behaviour as expressed through information search/seeking and information use. Given item c above in which Cole (2011) identifies a twin process of sense-making and adaptation in information use to solve the 'human condition'(p. 1217), the expectation is that the formation of new knowledge would be ascribed as the rational outcome of this process. Cole's (2011) model did not capture this obvious factor of knowledge formation through sense-making and adaptation, and therefore left a weakness in its design. 
Cole's (2011) model itemised the components of the factors of information behaviour in detail, however, it neglected to include the most salient issue flagged up in its discourse. For instance, he avers that "the ultimate goal of presenting a [the] theory of information need is to contribute to...interlinking knowledge formation with the act of information search" ( $p$. 1216). The model subsequently failed to integrate this important factor of knowledge formation resulting from what it describes as components of information behaviour (i.e. search, seeking and use), in its design.

\section{A model of scientists information-seeking behaviour (Niu and Hemminger, 2012)}

Niu and Hemminger (2012) explored the interactions between user attributes, environmental context, and the information-seeking behaviour (ISB) of scientists seeking information relevant to their research from electronic sources. In their paper the authors posit that "a person's specific information action (which they classified as part of general information behaviour) is determined by a combination of attributes of the person, his or her environmental context, the information need, and his or her general information behaviour excluding the current specific action of interest" (p. 337). Niu and Hemminger (2012) described "psychological, social-role-related, and demographic characteristics" (p. 337) as attributes of the person that combine with information needs and environmental context to influence their information behaviour. The authors subdivided the strands that make up information behaviour into "information searching, information using, and information collecting" (p. 337).

Niu and Hemminger's (2012) model serves as a good medium in understanding what influences people's information behaviour within a specific context. However, within a broader context of information literacy, some salient concerns which the model has not addressed are: a) what prompts the information need, i.e. what is the basis for the need? b); what influences information behaviour? c); and, what is the outcome of information behaviour as evidenced through specific information actions? These are concerns which Wilson (1981, p. 7) referred to as "the central question of information need".

Various other perspectives in IB discourse have portrayed information behaviour also primarily as a direct outcome of the interplay between information need and work/social role, with the latter as the foundation (Li and Belkin, 2010; Walton and Cleland, 2013). Li and Belkin (2010) consider the demands of different work tasks as the primary influence on users' interactive information seeking behaviour. This view implies that people's work/roles within society acts as the stimulus for engaging in information activities that denote their 
information behaviour. Consequently, the extent to which individuals are able to solve their information need is determined by that information behaviour (Case, 2007).

These perspectives indicate that scholarly views position information need as the start-off factor prompting information behaviour and information use. However, other intermediating and outcome factors associated with these concepts of information behaviour have not been exhaustively highlighted and discussed in previous IB models. The gap left by this failure in emphasis by previous models makes imperative the development of a new model which integrates every factor identified from the IB literature as the causative and outcome factors of people's information behaviour. This provides a tool for better understanding people's information behaviour within a properly integrated explanatory context.

\section{The concept of information literacy}

Discourses on the meaning and applications of information literacy have not achieved a universal definition, although common understandings about the practical uses exist. Perspectives however, converge around some predominant frameworks espoused by: the Association of College and Research Libraries (ACRL) of the American Library Association (ALA) (2000); Australian and New Zealand Information Literacy Framework (ANZIIL) (2004); and, SCONUL’s (2011) seven Pillars of Information Literacy.

The ANZIIL (2004) framework for example, avers that the information literate person is effective and efficient in locating information, having first recognised its need; and determined its nature and extent. The document also avers that the person is then able to combine prior and newly obtained information, for generating new understandings for application in context; and complying with all obligations surrounding the appropriate use of information (p. 11).

Information literacy has also been portrayed as a person's knowledge of the values of information, expressed through purposeful access to appropriate information sources in problem-solving and learning contexts. Ojedokun (2007) characterises information literacy as a prerequisite of the modern information society which is based on intelligent identification, location, perception, appraisal and usage of information for lifelong learning. Lloyd (2010a) in contrast, perceives information literacy as a socio-culturally ingrained practice and a type of learning that occurs within situated contexts of specific communities. These communities facilitate learning opportunities through social interactions which afford people information 
and new knowledge. This mode of learning from belonging to a community goes beyond a mere possession of operational information search skills, to developing a capability for practical, manoeuvrable application of information in everyday roles (pp. $24 \& 104$ ).

\section{Becoming information literate}

Becoming information literate is a process that leads to empowering people with ability for taking best possible decisions in the application of knowledge to specific problem-solving contexts requiring information. Walton and Cleland (2013) outlined what characterises becoming information literate as someone being able to complete specific tasks by interacting with information sources to express "the interplay of an individual's behavioural, cognitive, metacognitive and affective states" in determining "the level of new knowledge learnt (or produced, or both) and the degree of changed behaviour (i.e. level of information literacy exhibited)”( (p. 23).

Becoming information literate is a process shaped by multiple factors, social, psychological and cognitive, defined and applied within specific contexts. Current information behaviour discourse elicits divergent perspectives in the mode of learning through which people become information literate. This could be classified into two broad perspectives - instructional and interactionist. These two main perspectives are further discussed:

\section{Library-centred (bibliographic) perspective of information literacy learning}

Authors advocating the instructional view believe in the primacy of tuition in people becoming information literate. Some of the authors who champion the perspective that the library and librarians are the best agencies to lead the process of promoting information literacy skills include Welsh and Wright (2010); Burke (2010); and, Andretta (2005). These authors project an emphasis on bibliographic skills instruction by librarians, for learners to acquire information literacy capabilities, enabling them become skilled life-long users of information.

Librarians have for over three decades promoted skills instruction as the primary route to becoming information literate. However, in the last decade this notion has come under increasing scrutiny from scholars. For example, Gorman and Dorner (2006) discountenance an over-emphasis on functional skills in relation to competence in information literacy practice, arguing that the emphasis should be on integrating information within various tasks rather than on skills acquisition. Bawden (2011) seems to provide a middle-ground in the debate by proposing that, there can be no widely shared conclusions, given the difficulty in 
determining who makes the most contributions to the process of becoming information literate. The librarian-centric perspective was similarly queried by Shih (2012) who infers that "a successful information literacy education requires collaborative efforts from stakeholders including librarians, information technologists, faculty members, and media specialists" (p. 285).

The debate on whether information literacy learning centred on bibliographic skills instruction adequately prepares students for a "purposeful, successful, interaction with the world around them" continues (Hepworth and Walton, 2009, p. 27).

\section{Social interactionist perspective of information literacy learning}

The social interactionist perspective considers information literacy as common to and situated in all environments; including educational, social and the workplace. This perspective disagrees with the notion that becoming information literate primarily results from bibliographic skills instruction. Lloyd (2010a) and Hepworth and Walton (2013) are some of the scholars who canvass this perspective. Hepworth and Walton (2013) argue that the concept of information literacy is increasingly being taken out of the traditional educational or library context and into the workplace with current emphasis on the individual's attitudes and capabilities in managing, organizing, sharing information and knowledge, rather than bibliographic search skills. Lonka (2012) also advances this perspective of context relevance with the view that "learning always takes place in a context which is situational, but relies on culturally and historically developed structures, and that human beings have evolved in such a way that their normal cognitive development depends on a certain kind of cultural environment for its realization" (p. 15).

This perspective de-emphasises skills instruction to highlight a more social interactionist mode of learning which enables individuals become information literate in a broader context. The interactionist concept canvasses people's active participation within the wider social context or setting of a defined community, as means for acquiring information skills relevant for application to real-world situations of everyday life.

Information literacy under the interactionist perspective envisages a conscious albeit a learning process de-emphasising structure; more often than in in the bibliographic skills method, affording serendipitous learning. This learning mode affords a person within a community, the ability to effectively engage with and utilise the information sources and 
resources within that community, for meeting information needs and knowledge formation. Information literacy is mainly perceived in this domain of learning as a context-defined, context-shaped, and context-applicable ability. This ability relates to people locating, accessing, modifying or transforming information to suit specific situations. Within this perspective, information literacy is seen as embedded in all facets of the society; including the workplace.

Lloyd (2010a) underscored this perspective in stating that: "information literacy is a practice that is construed through a constellation of affordances, information activities and skills, which together enable a way of knowing the modalities of information that constitute an information environment" (p. 168). This view of information literacy as a learning process situated in social interactions has progressively been canvassed such as by Hoyer (2011) who suggests refraining from "an information literacy instruction model that emphasises the use of specific tools and the acquisition of a set of skills [because it] will not be adequate in a setting where social relationships are important for finding and evaluating information" (p. 12).

This perspective asserts the equality of social relationships and skills instruction in people's development of information literacy capabilities. Additionally, social interactionists consider learning as a continuous process that requires both mentoring and collegiate knowledge sharing in situated learning contexts to be maximised. The situated learning concept affords knowledge through processes of mentored activities and reflection, particularly for people who participate as members of a community of practice (Torras and Saetre, 2009, p. 81).

This social participation affords the learner opportunity for information sharing for the conception of new knowledge. In this perspective information literacy surpasses an individual's possession of mainly a set of transferable information search skills, particularly those that are related to the classroom; taught in librarian-led information literacy instructions. It reflects Lloyd's (2010a) view of information literacy as a socio-cultural practice transcending mere possession of a set of skills to a complex understanding of the social modalities that influence the learning and application of information in specific contexts ( $\mathrm{p}$. 24). Mutch (1997) in similar vein argues that information literacy is sensitive to context and is a continuum of learning where individuals do not necessarily need the same skills.

The social interactionist perspective infers that a holistic information literacy capability cannot be adequately demonstrated by people who possess limited set of bibliographic 
information skills suited only to specific contexts. This perspective is given that "information best practices are highly dependent on the context in which individuals find themselves" (Hoyer, 2011, p. 21). This perspective infers that people become information literate through multiple information-generating activities within their social environments. What is considered most essential is not whether a person receives formal information literacy tuition, but the ability to apply information literacy to problem solving, and adaptation to other contexts of information need. The perspective envisages information literacy as providing ability for deploying the skills obtained from diverse information affordances for a continuous learning and problem-solving throughout life.

The overarching argument in the social interactionist perspective tends to be that information literacy is a competence learned in practice and embedded in social interactions "located within and through group activities" (Lloyd, 2010b, p. 250). This method of learning is deemed as occurring within different types of social settings and in different learning situations. As an ingrained ability acquired and displayed in practice and everyday life, this perspective envisions information literacy as a reflection of a part of the routines of individuals and groups in the society, which supports achieving effectiveness in the discharge of personal, educational and workplace tasks.

\section{Domains of the information literacy learning process}

The debate about how best to achieve information literacy continues in the literature with scholars developing models to demonstrate how people become information literate; using different perspectives, and with emphasis on different contexts.

For example, Walton and Cleland (2013) propose a three sphere model of information literacy to explain how individuals become information literate in a wider social context. Walton and Cleland consider (2013) each sphere consisted of: a) find/access/locate; b) evaluate/discern; and, c) use/communicate/produce, as intertwined with each other, contributing to the entire process of learning which occurs in no particular sequence. The authors explained that variations could occur in the degree of importance of each domain at certain points. They portray information literacy learning as an interconnected process that impacts on a person's ability to be a lifelong learner.

Hepworth (2000) canvasses the need for the information literate person to possess a balanced and integrated knowledge base. Hepworth (2000) posits that this balance will result from 
people's interactions with different knowledge domains in the information literacy learning process. This interaction is envisaged to foster understanding in learners of the theoretical and practical implications of information use. Information literacy learning from this dimension also de-emphasises the primacy of bibliographic instruction; suggesting that the influences of other learning domains are correspondingly useful in the learning process.

Hepworth (2000) explains that learning how to use information tools, includes learning the purpose and functionality of ICT and also the use and navigation of physical information media. The second domain is described as learning the intellectual process which leads to creating knowledge and managing information. The third domain, 'learning how to communicate' emphasises the interpersonal skills associated with effective gathering and exchange of information and knowledge (i.e. team work, negotiation, listening, collaboration and training) using appropriate communication styles. The fourth domain espouses learning the intellectual norms of the subject domain' related with knowledge production.

Hepworth's (2000) model conceives the information literacy learning process as a combination of these strands of impact on an individual. These domains represent the cognitive, behavioural, cultural and social factors which shape the individual's information capability. Experiencing this multi-dimensional impact during information literacy learning was considered imperative for producing an effective information user. A holistic learning of information literacy anchored on Hepworth's (2000) four domains appears important.

\section{The usefulness of information literacy}

The predominant perspective of information literacy situates the concept as a learned ability that translates to the possession of lifelong capacity to solve information-related problems. This capacity affords people the skills to adapt in society and to elicit knowledge from their information environments for practical uses. The information people receive, make sense of, and use appropriately, generates new knowledge which is applied to problem-solving and for decision-making in different circumstances (Lloyd 2010a; Walton and Cleland, 2013; Bruce, 1999). The Alexandria Proclamation on Information Literacy and Lifelong Learning echoes the multi-dimensional relevance perspective of information literacy by articulating that:

"Information literacy lies at core of lifelong learning. It empowers people in all walks of life to seek, evaluate, use and create information effectively to achieve their personal, social, occupational and educational goals" (IFLA, 2005, p. 1). 
Effectively achieving these personal, social, occupational and educational goals require a perceptible use of information literacy in solving problems. Lloyd (2003) refers to this multicontext ability to apply information literacy as 'meta-competency'; a perspective which infers that people can apply information to useful purposes in the workplace, for overcoming all "cognitive and environmental barriers" (p. 90).

In today's world, information sources and new knowledge are now rapidly produced from many sources and delivered in an ever changing landscape, scaffolding advances in modern technology. In this information landscape, Hepworth (2000) posits that information literacy is necessary because we live in a changing world of "information intensive economies" with greater emphasis on "improving the intellectual processes associated with data, information and knowledge management in the workplace" (p. 22). Realising when there is a genuine need for information is a competence an information literate person is expected to exhibit (Welsh and Wright, 2010).

\section{Information behaviour, information literacy, and knowledge: contrasting or complementing?}

Information behaviour has been defined as how people behave towards seeking information in situations of information need (Mutshewa, 2007; Salman et al., 2013). Information behaviour reflects in "those activities a person may engage in when identifying his or her own needs for information, searching for such information in any way, and using or transferring that information" (Wilson, 1999, p. 249), and is characterised by people's perspectives on the value of information use in solving the problems of everyday life.

Commonly shared views indicate that people have different experiences in diverse information-seeking environments and contexts, and use the information they obtain in different ways (Line, 1998; Lloyd, 2010a). A factor commonly associated with people's information behaviour is information needs; itself necessitated by the various activities people take on in their life-world. Information behaviour is influenced by factors such as the situation that prompts the need, and other social, cognitive and personal circumstances (Wilson, 1997, 1999; Spink, 1997; Sonnewald and Livonen, 1999) including being information literate (Lloyd, 2010a). Information behaviour could also be determined by the type of information need triggered by the life-world activities and the culture of individuals or groups of people. 
Hepworth and Walton (2009) explain the influence of culture as a concept that "encompasses the wider set of ideas, attitudes and norms that tend to influence people's information behaviour" (p. 118). Within a cultural environment, people develop awareness related to specific information needs and the desire to satisfy those needs. The defining characteristic which information literate persons will demonstrate within each of these specific environments is an "awareness of how they gather, use, manage, synthesise and create information and data in an ethical manner" with appropriate information skills needed to be effective in doing so (SCONUL, 2011, p. 3). This perspective indicates that the capability to make appropriate choices of information sources; otherwise a person's information behaviour, is afforded by being information literate.

Consequently, tendencies of information avoidance; a negative information behaviour, may be attributable to possessing inadequate information literacy skills, for accessing and utilising information. Also the information behaviour of individuals exposed to the same life-world environment could differ, owing to differences in ability to assimilate information available in their environments; through formal and informal affordances. In the informal setting, these differences in ability to gather and utilise the information obtainable within a socio-cultural environment; bellies individual commitments and desire to information-seeking, in the social interactionist form of information literacy learning.

Case (2007) posits that individuals do not compulsorily "think, feel, or do something about" the information at their disposal because "informed behaviour does not always result from exposure to information" (pp. 98-99). According to Line (1998) "all people are individuals, and will seek and use information in different ways" (p. 223). The factors that generate these differences of information behaviour in people also include: environmental, cognitive, affective and social factors (Allen, 2011; Niu and Hemminger, 2012).

The description of information literacy by IFLA/ALP (2007) as a self-empowering attitude of individuals to commit to: accessing, analysing, translating, and transforming information to create knowledge for problem solving and achieving personal, social, learning and occupational goals; echoes the important influence of information literacy on information behaviour. This and related views mentioned earlier in this paper, indicates that knowledge formation resulting from the processes involved in solving information needs has been part of the information behaviour discourse. The problem is that existing models of information behaviour, have severally failed to integrate 
information literacy; an important factor in information behaviour, in their designs and discourses, thereby creating a gap in understanding.

Information need arises "where individuals recognize gaps in their states of knowledge and in their ability to make sense of an experience" (Detlor, 2003, p. 116). Case (2007) citing Dervin (1983) infers that information need implies "a state that arises within a person, suggesting some kind of gap that requires filling. When applied to the word information, as in information need, what is suggested is a gap that can be filled by something the needing person calls "information” (p. 75). A good example of the use of Dervins's Sense Making, Micro Moment Time Line methodology in healthcare can be found in (Hepworth and Harrison 2004). Their exploration of Information Needs of People with Multiple Sclerosis using Dervin's method was instrumental in uncovering a vast array of differing information needs and gaps in provision. People use a variety of strategies to obtain desired information depending on the importance of the information need, and the amount of time available (Sohn et al., 2008). The strategies used are intermediated to a large degree by the information literacy capability at the disposal of individuals. The understanding that knowledge gap needs to be filled "precipitates an interest in related information as well as the motivation to acquire it" (Zerbinos, 1990, p. 922).

It is on the basis of an established information need that a person or groups may engage in a search for information across various sources to solve the need. Hughes et al. (2010) explain that information search is a process by which a person seeks knowledge about a problem or situation. The exact information seeking activities and sources individuals are inclined to using in this search process is characteristic of their information behaviour, which itself is influenced by information literacy. An information literate person is deemed able to frame questions appropriate for obtaining information from the right sources in an information search. This is in addition to possessing competence for interrogating and eliciting new knowledge from the sources of information obtained from the search. Information literacy enables individuals to effectively discharge personal roles, workplace assignments and expectations in the society through adequate information use. According to Whitworth (2009) "the information literate person is not just a conduit of information, but is actively using it and enhancing it, for their own benefit" (p. 96). Conversely, this implies that people would be ineffective in meeting their information needs in the absence of information literacy competence. 
A contrasting, albeit not mainstream perspective suggests that there are factors which cause people to avoid an information, regardless of their information needs. Nicholas and Herman (2009) who proposed this perspective of information avoidance in people's information behaviour state that:

\footnotetext{
"Clearly, in today's internet-based information world, in which information is being generated in ever-increasing volumes and people are connected to information sources of unparalleled power and reach, taking a conscious decision not to attempt to meet one's information needs, at least not fully, is commonplace and will increasingly become more so" (p. 19).
}

Although this is apparently a minority perspective in information behaviour discourse, it nonetheless, aligns with a long-held belief that availability of information should be complemented by competence and knowledge of users for engaging constructively with appropriate information sources. The desire to pursue or ignore information needs is believed to be dependent on an individual's competence in identifying the information need and framing that need in a searchable format for self-search or through an intermediary (Davies, 2007, p. 84). This perspective indicates that knowledge of search modalities is crucial to a search for obtaining information towards meeting information needs. Aforementioned perspectives on information literacy overwhelmingly suggest that that knowledge of search modalities for accessing needed information is afforded by being information literate.

\section{New Model}

\section{The causative and outcome factors of information behaviour (COFIB)}

This paper presents the rationale and subsequent development of a new information behaviour model entitled the Causative and Outcome Factors of Information Behaviour (COFIB). COFIB contributes to IB literature base by highlighting information literacy and knowledge in people's information behaviour. The model was presented in Figure 1 and it is replicated in Figure 2 below. 


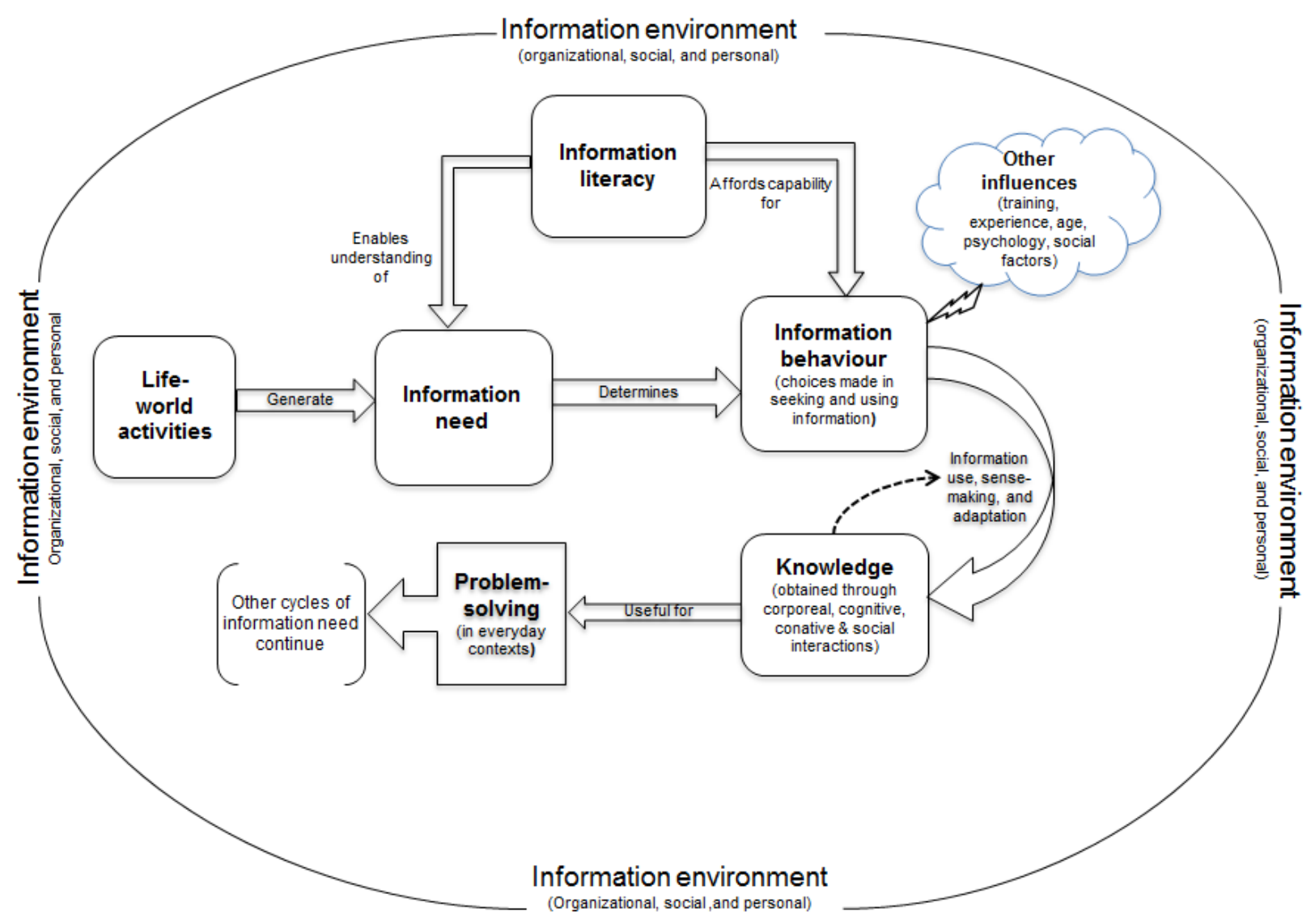

Figure 2: The causative and outcome factors of information behaviour (COFIB) model

The starting point for), the COFIB model is Wilson (1981) Wilson presents the activities of a "user's life world" which is described as "the totality of experiences centred upon the individual as an information user" (p. 6), as the prompt for their information needs. The COFIB model premises on this concept to suggest a user's life-world activities in place of work and social role (Wilson, 1997; Detlor, 2003) as the prompt (and context of) information need. This aspect suggests that in life, people engage in a cumulative set of daily activities within specific societies and cultures that constantly influence their perspectives, values, and orientation to information seeking and use. These societies would include people in an “insulated world of mutual support" (Chatman, 1999, p. 207). These activities occur in a broader sense than their work and social roles as they might relate to other issues such as; civic responsibilities, emotional, welfare, politics, and economic factors, and other encounters that could prompt information needs.

In general, the COFIB model agrees with the perspective in the previous models that information needs initiate human information behaviour; in the sense that needs for information generate the desire for information seeking to meet those needs (e.g. as indicated in Wilson, 1981, p. 4). The type of the information need prompted by the life-world activity, 
has the potential to determine which choices of information-seeking individuals make in resolving the need. The 'need' for information, results consequently from the pressure emanating from perceived insufficient knowledge, or a complete gap in knowledge (Belkin, 1980), that an individual or groups experience in relation to achieving effectiveness and/or satisfaction, over those life-world activities. The COFIB model infers that these processes take place within the information environment where individuals interact. This information environment consist of personal, social, or organizational, and in some cases; a combination of all the facets.

Building on Lloyd (2010b), the COFIB model posits that the capability for individuals to express information behaviour to satisfy their information needs is afforded by information literacy. The COFIB model further avers that information literacy serves as basis for understanding information needs within clearly defined problem contexts (e.g. as reflected in Bruce, 1999). A number of models have explained how people search information in order to meet their information needs e.g. Bates (1989) 'berrypicking techniques'; where searching for information is likened to picking individual berries from several bushes. Using this method means that the information is collected piece by piece and allows for the search to modified and altered as the search develops. Marchionini's (2006) 'lookup-learn-investigate' is also a step by step method for information searching and analysis. However, these stages usually, (but not comprehensively) include, fact retrieval - knowledge analysis and finally planning. The different techniques in these models vary in their depth. Information literacy enables completing these information search activities and should be an integral part of performing complex searches.

The COFIB model outlines the role of information literacy as two-fold. First, information literacy is necessary in order to define and clearly articulate the occurring information need. A lack of information literacy could pose a barrier to outlining information needs as well as to information seeking behaviour. Hence, the realisation and understanding of information needs require information literacy. Second, the COFIB model argues that information literacy provides people with the capability to seek, search, examine, scrutinise and select information in order to make an informed decision leading to fulfilling the task and the initial information need. In the current information era, data and information are readily available and easily accessible. However, the quality and the credibility of sources and information are prominent issues and challenges. Therefore, to be able to search for information and to assess its quality, relevance and credibility, information literacy is required. Therefore, the COFIB model 
emphasizes that information literacy is an important factor that intermediates users' information needs and their information behaviour, given that information literacy scaffolds the choices and actions of individuals about information sources and its use, in pursuit of their information needs.

Information literacy would also facilitate knowledge formation through information behaviour, as information literacy is needed to assess information, make sense of the information and apply the information, which results in knowledge production. The COFIB model clearly emphasizes the stage of knowledge formation in information behaviour. Other IB models (Wilson, 1981; 1997; Detlor, 2003; Niu and Hemminger, 2012) assume that after information behaviour takes place, the problem is solved and therefore, omit the stage of knowledge formation. The COFIB model resolves this by highlighting knowledge formation as the final outcome of the expression of information behaviour through information use, sense-making and adaptation. This view relates to the concept of learning as described by Marchionini (2006).

Sense-making and adaptation were concepts used in Cole (2011) but not in relation to knowledge formation. The COFIB model further draws perspectives from Weick et al. (2005) suggesting that knowledge formation results from a combination of the effects of sensemaking, adaptation and use of the information obtained through expressing information behaviour. The COFIB model also indicates that the knowledge base which develops through this process inversely influences capacity for better sense-making and adaption of information. This is portrayed as an iterative process through the dotted lines.

Sense-making and adaptation are concepts connected with using information appropriately. Sense-making is defined as "turning circumstances into a situation that is comprehended explicitly in words and that serves as a springboard into action", furthermore it involves "the interplay of action and interpretation" (Weick et al., 2005, p. 409). Put differently, this perspective connotes that sense-making involves individuals interpreting the information they obtain through their information behaviour to guide their actions. Adaptation, a concept closely related to sense-making, has been defined in Strobach and Carbon (2013, p. 1) as "the ability to adjust to novel information and experiences ...essential for living and surviving in...the human ecosystem". Taken together, the two concepts - sense-making and adaptation - in the use of information, potentiate knowledge formation, with knowledge subsequently serving as the basis of action, i.e., in problem- solving contexts. It is further recognised that 
this knowledge is obtained through multiple affordances; corporeal, cognitive, conative and social interactions.

This salient perspective is precisely expressed in the COFIB model to underscore its distinctive views highlighting the important role of knowledge in information behaviour.

The idea of sense-making suggests that people could be disparate in what results from their information behaviour. Several factors could be responsible for influencing the outcome of sense-making by individuals during information use. Following the views of Warner and Bath (2015, p. 93) and also Bawden and Robinson (2011, p. 128), the various factors capable of causing disparate outcomes in information behaviour were enunciated in the COFIB model as 'other contextual influences'. Bawden and Robinson (2011, p. 128) suggest that the differences in the information behaviour of people are intermediated by a variety of factors such as: age, gender, socioeconomic status; role; educational level and occupation; including also, personality factors, learning, and thinking styles. Burnett and Jaeger (2011, p. 162) similarly posit "larger social influences, including public sphere institutions, media, technology and politics", as part of factors which shape information behaviour. These influences predispose individuals to behaving in specific ways towards information search and use, and the sense they make out of this process, even if participating in the same or similar information environments.

The COFIB model further argues that the knowledge produced through information behaviour practice leads to the resolving of the initial problem and information need. It further explicitly stresses that this process is iterative. This is found to be a great omission in the majority of the existing IB models (a notable exception is Detlor's (2003) model). The COFIB model posits that through the cycle of information behaviour, knowledge gets formulated and accumulated leading to problem-solving. In a subsequent iteration, this knowledge would change people's information behaviours in that the accumulated knowledge would help to outline information needs more quickly and easily and act upon these to fulfil the necessary tasks. Therefore, IB should be seen a dynamic processes, not a static and linear one. This is strongly emphasised in the newly developed COFIB model.

The COFIB model has prominently highlighted salient features of information behaviour, by discussing the place of knowledge and its role in the solution of life world problems requiring appropriate information use. Knowledge formation has been mentioned in IB discourses but 
has not been integrated in the designs of previous IB models. The COFIB model presents knowledge as the basis for effective problem-solving in people's life-world through appropriate use of the information obtained by expressing information behaviour.

\section{Conclusions}

This paper has highlighted that a weakness in the reviewed IB models is the non-integration of information literacy and the formation of new knowledge for users in their designs. The paper has developed the new model, the COFIB model, which closes this gap. The integration of information literacy and knowledge within the COFIB model makes it distinctive from other IB models and provides an integrated, detailed explanatory framework of IB. This is the distinctive contribution of the new COFIB model to the literature base. With the integration and highlighting of the roles of information literacy and knowledge, the COFIB model, can, therefore, be considered a positive and welcome addition that anchors a broader understanding of people's information behaviour in diverse contexts.

\section{Implications of the COFIB model to research and understanding of people's information behaviour}

The COFIB model broadens the existing landscape of visualizing and explaining the factors of people's information behaviour as canvassed in previous information behaviour models. The inclusion of information literacy and knowledge in the COFIB model as factors associated with information behaviour, harnesses the factors integral to people's information behaviour, that were omitted in previous models. The COFIB model brings together disparate scholarly discourses on these concepts of information literacy; information needs; information behaviour; information use; and, knowledge; into a singular explanatory framework.

This unique integration of concepts that previously appeared as disparate in information behaviour discourses, into a singular model, generates a broader understanding of the interplay among the concepts that influence people's information behaviour. It could also influence future research into the contextual relationships among these factors in diverse information environments of individuals and groups.

COFIB is a useful integrated framework explaining the links between the various concepts in information behaviour. However some of these links were informed mainly by the literature. Future empirical research could address this by applying the model in various environments. 


\section{References}

Allen, D. (2011), "Information behaviour and decision making in time-constrained practice: a dual-processing perspective", Journal of the American Society for Information Science and Technology, 62, 11, 2165-2181.

Andretta, S. (2005), Information literacy: a practitioner's guide, Oxford, Chandos Publishing.

Australian and New Zealand Institute for Information Literacy (2004), Australian and New Zealand information literacy framework: principle, standards and practice 2nd ed., Adelaide, Australian and New Zealand Institute for Information Literacy (ANZIIL) and Council of Australian University Libraries.

Association of College and Research Libraries (2000), Information literacy competency standards for higher education, Chicago, Illinois, American Library Association.

Bates, M. J. (1989), "The design of browsing and berrypicking techniques for the online search interface", Online Review, 13, 5, 407-424.

Bawden, D., and Robinson, L. (2011), "Individual differences in information-related behaviour: what do we know about information styles?" in Spink, A., Heinstrom, J. (Eds.), New Directions in Information Behaviour, (Library and Information Science), United Kingdom: Emerald group Publishing, 127-158.

Belkin, N. J. (1980), "Anomalous States of Knowledge as a basis for information retrieval", The Canadian Journal of Information Science, 5, 133-143.

Belkin, N. J. (1995), "Cases, scripts, and information seeking strategies: on the design of interactive information retrieval systems", Expert Systems with Applications,9, 379395.

Bruce, C. S. (1999), "Workplace experiences of information literacy", International Journal of Information Management, 19, 33-47.

Burke, M. (2010), "Overcoming challenges of the technological age by teaching information literacy skills”, Community \& Junior College Libraries, 16, 247-254.

Burnett, G., and Jaeger, P. T. (2011), The theory of information worlds and information behaviour, in Spink, A., Heinstrom, J. (Eds.), New Directions in Information Behaviour (Library and Information Science Volume 1), United Kingdom: Emerald Group Publishing.

Case, D. O. (2007), Looking for information: a survey of research on information seeking, needs and behaviour $2^{\text {nd }}$ ed., Amsterdam, Elsevier. 
Chatman, E. A. (1999), "A Theory of Life in the Round", Journal of the American Society for Information Science, 50, 3, 207.

Choo, C. W. (2006), The knowing organization: how organizations use information to construct meaning, create knowledge, and make decisions $2^{\text {nd }}$ ed., Oxford, Oxford University Press.

Clarke, M. A., Belden, J. L., Koopman, R. J., Steege, L. M., Moore, J. L., Canfield, S. M., and Kim, M. S. (2013), "Information needs and information-seeking behaviour analysis of primary care physicians and nurses: a literature review", Health Information and Libraries Journal, 30, 178-190.

Cole, C. (2011), "A theory of information need for information retrieval that connects information to knowledge", Journal of the American Society for Information Science and Technology, 62, 7, 1216-1231.

Davies, K. (2007), “The information-seeking behaviour of doctors: a review of the evidence", Health Information and Libraries Journal, 24, 78-94.

Dervin, B. (1992), From the mind's eye of the user: The sense-making qualitativequantitative methodology, in Glazier, J. D., Powell, R. R. (Eds.), Qualitative Research in Information Management, New York: Knowledge Industry Publications.

Detlor, B. (2003), "Internet-based information systems use in organizations: an information studies perspective", Information Systems Journal, 13,113-132.

Godwin, P., and Parker, J. (2012), Information literacy beyond library 2.0., London: Facet Publishing.

Gorman, G. E., and Dorner, D. G. (2006), "Information literacy education in Asian developing countries: cultural factors affecting curriculum development and programme delivery", Paper delivered at the World Library and Information Congress: 72nd IFLA General Conference and Council 20-24 August 2006, Seoul, Korea, available at: http://www.ifla.org/iv/ifla72/index.htm:1-19 (accessed 12 December 2015).

Hepworth, M. (2000), “Approaches to providing information literacy training in higher education: challenges for librarians", New Review of Academic Librarianship, 6, 1, 21-34.

Hepworth, M. (2007), "Knowledge of information behaviour and its relevance to the design of people-centred information products and services", Journal of Documentation, 63, 1, 33-56. 
Hepworth, M., and Harrison, J. (2004), "A survey of the Information needs of people with Multiple Sclerosis”, Health Informatics Journal 10, 1, 49-69

Hepworth, M., and Walton, G. (2009), Teaching information literacy for inquiry-based learning, Oxford: Chandos Publishing.

Hepworth, M., and Walton, G. (2013), "IL and IB, complimentary approaches for building capability", M. Hepworth and G. Walton, Developing people's information capabilities: fostering information literacy in educational, workplace and community contexts, United Kingdom, Emerald.

Horton Jr., F. W. (2011), “Information literacy advocacy - Woody's Ten Commandments", Library Trends, 60, 2, 262-276.

Hoyer, J. (2011), "Information is social: information literacy in context", Reference Services Review, 39, 1, 10-23.

Hughes, B. Wareham, J., and Joshi, I. (2010), "Doctors' online information needs, cognitive search strategies, and judgments of information quality and cognitive authority: how predictive judgments introduce bias into cognitive search models", Journal of the American Society for Information Science and Technology, 61, 3, 433-452.

IFLA (2005), Beacons of the information society: the Alexandria Proclamation on Information Literacy and Lifelong Learning, available at: http://www.ifla.org.files/wsis/Documents/BeaconInfSoc-sl.pdf $\quad$ (accessed 18 December 2015).

IFLA/ALP (2007). Sub-Saharan Africa, colloquium on information literacy and lifelong learning. Helena Asamoah-Hassan Ed. 29th-30th April. Addis-Ababa, Ethiopia.

Ingwersen, P. (1996), "Cognitive perspectives of information retrieval interaction: elements of a cognitive IR theory", Journal of Documentation, 52, 3-50.

Kuhlthau, C. C. (1991), "Inside the search process: Information seeking from the user's perspective". Journal of Documentation, 49, 4, 339-355.

Kuhlthau, C. C. (1993), "A principle of uncertainty for information seeking”. Journal of the American Society for Information Science, 42, 5, 361-371.

Li, Y. and Belkin, N. J. (2010), "An exploration of the relationships between work task and interactive information search behaviour", Journal of the American Society for Information Science and Technology, 61, 9, 1771-1789.

Line, M. B. (1998), Designing libraries round human beings, Aslib proceedings, 50, 8, 221229. 
Lloyd, A. (2003), "Information literacy: the meta-competency of the knowledge economy? an exploratory paper”, Journal of Librarianship and Information Science, 35, 87-92.

Lloyd, A. (2010a), Information literacy landscapes: information literacy in education, workplace and everyday contexts, Oxford, Chandos Publishing.

Lloyd, A. (2010b), "Framing information literacy as information practice: site ontology and practice theory" Journal of Documentation, 66, 2, 245-258.

Lonka, K. (2012), "Engaging learning environments for the future, the 2012 Elizabeth W. Stone Lecture", in Gwyer, R. Stubbings, R. and Walton, G. (Eds.), The road to information literacy: librarians as facilitators of learning, The Hague, the Netherlands, De Gruyter Saur, IFLA Publications 157.

Marchionini, G. (2006), "Exploratory search: from finding to understanding", Communications of the ACM, 49, 4, 41-46.

Mutch, A. (1997), "Information literacy: an exploration", International Journal of Information Management. 17, 5, 377-386.

Mutshewa, A. (2007), "A theoretical exploration of information behaviour: a power perspective", Aslib proceedings, 59, 3, 249-263.

Nicholas, D. and Herman, E. (2009), Assessing information needs in the age of the digital consumer, 3rd ed., London, Routledge.

Niu, X., and Hemminger, B. M. (2012), "A study of factors that affect the informationseeking behaviour of academic scientists", Journal of the American Society for Information Science and Technology, 63, 2, 336-353.

Ojedokun, A. A. (2007), Information literacy for tertiary education students in Africa, Ibadan, Third World Information Services.

Salman, S. B. N., Ahmed, S., and Khan, A. (2013), "Information seeking in primary care: a survey of doctors working in remote government health facilities in Pakistan", Library Philosophy and Practice (e-journal), available at: http://digitalcommons.unl.ed/libphilprac/1009 (accessed November 26 2015).

SCONUL (2011), "The SCONUL Seven Pillars of Information Literacy Core Model for Higher Education, SCONUL working group on information literacy", available at: http://www.sconul.ac.uk/groups/information_literacy/seven_pillars.html (accessed March 17 2015).

Seeker, J., and Coonan, E. (2013), Introduction, rethinking information literacy: a practical framework for supporting learning, London, Facet Publishing. 
Shih, W. (2012), Student literacy for succeeding in a pervasive digital environment, the road to information literacy: librarians as facilitators of learning, The Hague, the Netherlands, De Gruyter Saur, IFLA Publications 157.

Sohn, T. Li, K. A. Griswold, W. G., and Hollan, J. D. (2008), “A diary study of mobile information needs", Computer Human Interaction, 433-442.

Sonnewald, D. H., and Livonen, M. (1999), "An integrated human information behaviour research framework for information studies", Library and Information Science Research, 21, 4, 429-457.

Spink, A. (1997), "Study of interactive feedback during mediated information retrieval", Journal of the American Society for Information Science, 48, 5, 382-394.

Spink, A. (2010), Information behaviour: an evolutionary instinct, London, Springer.

Spink, A., and Cole, C. (2006), "Human information behaviour: integrating diverse approaches and information use", Journal of the American Society for Information Science and Technology, 57, 1, 25-35.

Strobach, T., and Carbon, C. (2013), "Face adaptation effects: reviewing the impact of adapting information, time, and transfer", Frontiers in Psychology, 4, 1-12.

Torras, M., and Saetre, T. P. (2009), Information literacy education: a process approach, professionalising the pedagogical role of academic libraries, Oxford, Chandos Publishing.

Walton, G. and Cleland, J. (2013), "Becoming an independent learner", in Secker, J. and Coonan, E. (Eds), Rethinking information literacy: a practical framework for supporting learning, London, Facet Publishing.

Warner, P. V. J., and Bath, P. A. (2015), "The information needs and information behaviour of substance misuse care professionals in UK community teams", in Bath, P. A., spring, H., and Sen, Barbara (Eds.), Proceedings of the Seventeenth International Symposium for Health Information Management Research, 24-26 June 2015, York St. John University and University of Sheffield, York, United Kingdom, 93-103.

Weick, K. E., Sutcliffe, K. M., and Obstfeld, D. (2005), "Organizing and the process of sensemaking”, Organization Science, 16, 4, 409-421.

Welsh, T. S., and Wright, M. S. (2010), Information literacy in the digital age: an evidencebased approach, Oxford, Chandos Publishing.

Whitworth, A. (2009), Information obesity, Oxford, Chandos Publishing. 
Williams, D. (2005), "Literacies and learning", P. Levy, S. Roberts, Developing the new Learning Environment: the changing role of the Academic Librarian, London, Facet Publishing.

Wilson, T. D. (1981), "On user studies and information needs", The Journal of Documentation, 37, 1, 3-15.

Wilson, T. D. (1997), "Information behaviour: an interdisciplinary perspective", Information Processing and management, 33, 4, 551-572.

Wilson, T. D. (1999), "Models in information behaviour research", Journal of Documentation, 55, 3, 249-270.

Wilson, T. D. (2000), "Human Information Behaviour", Informing Science, Special Issue on Information Science Research, 3, 2, 49-55.

Zerbinos, E. (1990), "Information seeking and information processing: newspapers versus videotext", Journalism Quarterly, 67: 920-929. 